\title{
VERNACULAR DRESSING AND \\ ENGLISH \\ RE-DRESSINGS: TRANSLATING NEEL \\ DARPAN
}

JHARNA SANYAL

Abstract: Our experience of Bangla literature of the $19^{\text {th }}$ century Bengal compels us to rewrite and expand the parameters of post-colonialism as a discourse. This discourse is not simply about texts produced after the colonial experience, but about responses to the colonial experience from the very moment of the cultural encounter. The post-colonial in Dinabandhu Mitra's Nil Durpan (1960) is 'a way of talking about the political and discursive strategies of colonized societies...' (Ashcroft, 2001:24). The politics and the strategy are evident in the preface of the play, which seems to be a translation of a 'subjunctive' English text. The first English translation of the play may be read along with the 'more faithful' later translation (1992) to recognize these ways of talking/representation. 
"Because if...the work was so injurious in its vernacular dress, was I not doing a public service by making such work in English?" (From the Address of the Reverend J. Long to the court before the sentence was passed) (Rao 1992: 148).1

Dinabandhu Mitra, one of the most powerful dramatists of the $19^{\text {th }}$ century Bengal, wrote his first play Neel Darpan $(1860)^{2}$ on the oppressive behaviour of the white Indigo planters in Bengal in the 1850s. The play revolves round an old landholder and his family: it graphically dramatizes the plight of that family and the peasants of Lower Bengal through scenes of physical torture, rape, madness and death.

The Bangla play was in itself a contemporary stage success. It however became historically and politically famous after it was translated into English as The Mirror of Indigo Planters (1861). The subsequent trial of Rev. James Long who confessed to have published and edited the translation (148) is a part of India's colonial history. It also testifies to the importance of translation in the project of the British Empire.

The preface to the play addresses the numerous indigoplanters who are offered the neel darpan ('the indigo mirror'), 'so that they may take a look, reflected in it' (183). Mitra transposes the social, political and economic situations affected by the tyranny of the indigo planters to a literary field superimposing 'readability' on the dispersed events of the time by translating the events into a play. That he was conscious of the transposition is evident in the title of the play, which offers darpan ('mirror') as the central image. He develops the preface on a metaphorical networking: the politics of this 
metaphorical recasting lies in elevating the local cultural markers to universal moral properties. The 'sandal paste' with which the selfish planters are requested to adorn their foreheads stands for benevolence. The European milieu, by such metaphoric use, is transposed to a Hindu field of signs. In his preface, Mitra employs this transitional strategy to invoke the universal 'moral' world of good and evil, right and wrong and thus rescues the issue of human relationships from the political identities of the dominator and the dominated. The contingent power structures, the legitimising identities that facilitate discriminatory credentials, collapse under the universal moral categories of good and evil. The ideas of 'good' and 'evil' are translated through the metaphors of 'lotus' and 'worm': the good 'sahibs', the good governors like Grant and Eden are the 'lotus' in 'the lake of civil service' and the indigo planters are the 'worms' eating into the fame of the British. The planters are warned that the good civilians like Grant, 'the very personification of Justice', will wield their judicial power to save the oppressed: 'Holding the sudarshan chakra in their own hands, they will rid the peasant of the evil demon Rahu, who has seized him, and causes him unbearable misery in the form of the indigo planter' (184). The planters and the civilians, the malevolent and benevolent 'sahibs' both are Indianized through metaphors and they internalise and submit to an expected pattern of behaviour. I would argue that in such use, the sign becomes the site of 're-territorialization'. The aliens are domiciled in the territory of Indian myths, the oppressor as demon and the protector as the sudarshan chakrawielding Krishna.

Mitra's preface is addressed to the Indigo planters as if waiting to be translated into English. Unless that is done the 
voice cannot be activated. As Long said in defense of the translation, "The ryot was a dumb animal who did not know his rulers' language" (Raos 1992 :149-50). The preface is an appeal; it is not a part of the play. It is meant to be read and therefore must be rendered in the language of the addressee. Dinabandhu Mitra, later awarded the title 'Raisaheb', would have made his prefatory appeal in the language of the colonizers. This subjunctive text therefore seems to wait to be written back into English. As for the play, a performance of the original Bangla play would be an effective translation. When the play was being staged in Lucknow (1875), after the rape scene in which a planter was humbled by a Muslim peasant to enrage the British audience, 'they crowded near the footlights' and a few British soldiers drew their swords and climbed on the stage. The show was then ordered to be withdrawn (3).

Neel Darpan, contrary to popular belief, is hardly the revolutionary 'pre-test' play it is championed to be. And although its invective is ostensibly against British indigoplantation owners, the political scheme of the plot owes more to middle-class conceptions of rebellious behaviour than the organized, though unsuccessful, subaltern uprising that the indigo movement of 1860 actually had been. That the vernacular play and the playwright were considered potentially innocuous is supported by the fact that Dinabandhu Mitra was awarded the title 'Raisaheb' for his service to the British Empire (in the postal department during the Lusai war) in 1871 (i.e. 11 years after the publication of his play). It is believed that he wanted to share the punishment of Long, but the court held Long solely responsible. Another report says that when the troop performing Neel Darpan in Lucknow had the fear that the English magistrate in the audience might be offended, 
it was assured by the magistrate that it had nothing to be afraid of: Dinabandhu Mitra was his friend (3). The proceedings and the result of the trial of James Long amply proved the greater political potential of the target language text than that of the source text.

If Mitra's play was written to appeal to the white planters, Long's publication was to warn the powers that be. In his address to the court before the sentence was passed, Long had said,

I can only state ... what is personal to myself as to the motives which actuated me to publish Nil Darpan, on the grounds of my being a Missionary an expounder of native feeling as expressed in the native press - a friend to securing peace for Europeans in the country - and a friend to the social elevation of the natives. (147)

We remember that the statement above is a part of Long's defense at the court. It is however interesting to note his prioritization of identities. He is a missionary, expounder of the native press, friend to both the parties, the Europeans and the natives. The 'social elevation of the natives' (147) was required to ensure the peace of the Europeans and to preach the gospel. He wrote: 'Christianity has as yet made comparatively little headway among the population of Bengal. In my own observation and experience one of the most prominent causes appears to be mental, moral and social degradation of the ryot' (Mitra 103). He had lectured on Peasant Degradation: An Obstacle to Gospel propagation (153). ${ }^{3}$ That he was thinking more in terms of the propagation of the Bible and 
political sagacity than for the cause of secular human concern is manifest in his situating the issue of oppression in a contingent political background.

Russia \& Russian influence are rapidly
approaching the frontiers of India (150) ... the
mere armies can no more secure the English in
India...my duty as a clergyman is to help the good
cause of peace ... by containing \& listening to their
complaints. (151)

This colonial project of translation was mainly political; it was an act of surveillance facilitating knowledge of and subsequent control over the dominated subject. By his own admission, Long had been submitting 'hundreds and thousands of Bengali Books during the last ten years to the notice of Europeans of influence', 'sending copies of all Bengali translations' and 'procuring vernacular books of all kinds for missionaries'. In the case of Nil Durpan there was nothing exceptional he had pleaded. He admitted to have '... edited (the translation) with a view of informing Europeans of influence, of its contents, as giving native popular opinion on the indigo question...'. He, of course, added that he had 'circulated it chiefly among men of influence in England and those connected with the legislature, which to the oppressed of whatever colour or country had always afforded sympathy \& redress' $(147-156)^{4}$. This sympathy and redress would also facilitate the prospect of propagating the Bible.

It was therefore the content of the text that mattered. Long wrote an introduction in which he explained the reasons for undertaking the venture, but there is hardly anything about 
the difficulties or the problems of translating such a culturally different text, nor anything about the translation strategies. The editorial presence is observed only in the passages 'expunged or softened' as they were found to be too coarse for or offensive to European taste. Such passages, Long had said, were the 'prominent ... defects in many Oriental works of high reputation' (Mitra 2001:101). There is a perfunctory glossary at the end of the translation; its inadequacy became obvious when Long had to explain in the courtroom certain culturespecific perceptions in order to assuage his offended readers. In Act I. Sc.4 of the play, one of the female characters belonging to the lower class makes disparaging remarks about Mrs Wood's (wife of the tyrant indigo-planter Wood) familiarity with the magistrate. The British took this to be a slur on their women: Long had to explain the difference in cultural/social perceptions in such matters and elucidate the problems of translation and reception of alien cultures in a - courtroom in Calcutta.

The translation as the title page shows is by "a native". However, he seems to be a native who had very little acquaintance with Bangla idioms, phrases or words. There are many inaccurate translations deserving to be called 'howlers'. Jf many such, I may mention two: a woman says, her husband lad offered her a 'bau'. This is a short form of 'bauti' or 'baju', $\downarrow$ variety of bangle. The word is phonetically close to 'bou', daughter-in-law. The 'native' translator translated the sentence as, '... He even wanted to give me a daughter-in-law'. The second is a literal translation of a Bangla idiom that means 'to go on a fast': 'I will not give rice and water to my body'. Such absurdities make out a strong case against the story that Michael Madhusudan Dutt was the 'native' translator'. In the 
seventies, several scholars argued convincingly against the claim (Sengupta1972 Preface viii-xxii). Even the British jury refused to believe that the translator was a native (Proceedings of the trial as printed in Pradhan 1997:114).

\section{II}

In 1992, Oxford University Press published a translation of the play in the book, The Blue Devil: Indigo and Colonial Bengal with an English Translation of Neel Darpan. Four editions were published in between the publications of Long and the Raos. ${ }^{6}$ All the four are reprints of Long's publication. The last two make alterations/corrections in the original translation, but the result is not always felicitous (Sengupta 1972: $x x \dot{x}$-xxxiii). The OUP edition is perhaps the first (post-Independence), and till now the last, direct translation from Dinabandhu Mitra's Bangla play.

Dinabandhu Mitra addressed the benevolent administrators and the oppressive indigo-planters and wrote to seek redress for the oppressed natives and to appeal to the administrators to salvage their fame. Long had similar motives behind the translation, but his readers were the 'Europeans of influence', and he intended his work to be also a warning against possible rebellion (his reference was to the Mutiny). The Raos, the authors of The Blue Devil felt the 'necessity for a modern annotated translation of the play to perceive the reality of the oppressive world Dinabandhu Mitra had portrayed' (12), and they declare that their translation is 'for all' (13). 
From a postcolonial/post-Independence perspective, the play acquires a fresh significance. With the change of historical context, the relevance of the play/translation is not lost, but altered. The title of the book indicates a changed perspective against which the translation is set: the historical backdrop, the context of the play, the documents of Long's trial and other such contemporary socio-political details become a part of the extended textuality of the play. The contents page provides the initial idea of this arrangement: seven chapters that deal with the colonial context precede the translation of the play. Such multilayered textual strategies are common in contemporary literary works intended for an intercultural audience. Embedded texts like footnotes/endnotes, glossary, and such other para-textual devices, (also called extratextual rewritings, or the translator's long hand - Editors), used in such literary translations and in post-colonial writings suggest that the differences between the two 'are more prima facie than they are upon close consideration' (Tymczko 2000:22).

The personal narrative of the authors relating to the conception and execution of the project of translation shows the way they had read a contemporary account of oppression in the play of 1860 . During their visits to the villages that were once the indigo-planting areas, they had heard various kinds of tales about the planters and their atrocities. 'Despite these exhilarating tales the villagers had lost all interest in those oppressors; new, indigenous oppressors, no less ruthless, had begun to take their place' (1-2; my emphasis). On the one hand, the authors situate the play on the local political/historical map (literally, the maps of colonial Bihar, the indigo-growing provinces are provided), and on the other; they release it from the local by connecting it to the global 
theme of oppression and exploitation that transcends time and space. The ideological stance is foregrounded through the quotation from Brecht, which precedes the contents page.

Thus, the function of this text differs from Dinabandhu Mitra's and Long's as well. Translation, as Snell-Hornby has aptly reminded us, is not a trans-coding of words or sentences from one language to another, but a complex form of action whereby the translator offers information on a source language text in an altered, new situation and under changed functional, cultural, linguistic conditions, retaining the formal aspects as far as possible (see Bassnett and Lefevere 1990: 82). The awareness of the difficulties involved in translating a text which is written in colloquial, dialectal and other varieties of language that a village community speaks (in fact, the language is difficult even for a modern day Bengali) is manifest in the translator's statement (11-13):

All translators face the difficulty of choice and unwittingly many tend to become creators of their own discourse rather than the faithful renderers of the original. We too faced this problem. We wanted our translation to be readable, but above all we wanted our text to stick to the original without altering the ideas or dispensing with local sayings, songs, idioms and mythological references. We have adhered to the text meticulously, but within permissible limits tried to clarify some points, so that they might be understood and appreciated by all (Mitra 1992:13). 
The authors have used notes and a glossary as supplementary texts to bring out the nuances of specific cultural and social practices. The innovativeness of the work lies in translating the different Bengali varieties used by the native and the English characters. In the original, the planters spoke a kind of patois, a nonstandard, corrupt form of Bangla that has been translated into a supposedly parallel nonstandard, 'corrupt' English. Irrespective of the distinction of their socioeconomic class and consequent difference in the language they speak, the natives are given Standard English speech. Here is an example:

Wood: Case nothing - this magistrate good man five years civil suit, case not end. Magistrate, my good friend. See, or evidence accept. New law use, four rascals jailed...

Gopinath: My Lord, Nabin Basu's helping the families of those peasants. He has lent his own ploughs, cattle and men to plough their land that they might not lose their crops (Mitra 1992: 217).

This stylistic strategy successfully meets the challenge of translating such a linguistically difficult text. However, in spite of all the labour and meticulous care they have taken for the publication, certain areas of incomprehension surface only through the process of translation. Translation in this perspective is a re-reading of the source language text in response to the demands of the target language. The 'native' translator often takes for granted certain expressions without trying to probe into their cultural stamp. This is particularly 
true of texts that deal with issues that are distant from our present day culture and concern. I refer

to three translations of a passage, each different from the other and the one in The Blue Devil is the worst, as, not only does it fail to translate it, it mistranslates it, fortifying the mistranslation with a historically false information as a 'note'.

In Act IV Sc. 2, on being questioned by the Deputy Inspector why the senior pundit could not be seen for some days, a pundit answers:

1. Long's edition ... It does not seem good for him now to go to and come from the college looking, with his books under his arms, like a bull bound to the cart. He is now of age. (Mitra 53; my emphasis).

2. (the above as it 'should have been' suggested by Shankar Sengupta);

... It does not look nice for him to come college (sic) when it is about time to erect for him the stake to which the bull of the sradh ceremony is tied (Preface xxxii; my emphasis).

3.. The Blue Devil version ... Besides it does not look nice to go to college every day with a bull's halter tied round one's neck and he is no longer young either (237; my emphasis)

For the expression I have emphasized, the translators add: 'This is a reference to the necktie, which was introduced by the Europeans' (270; note 2, Act IV).

The old Bengali proverb - to tie a brisakastha around one's neck - suggests extreme old age when a person bends 
double. ${ }^{8}$ 'Brishakastha' was a heavy wooden structure used for sacrificing bulls on sradh ceremonies. The sheer weight of the frame to be set about 3 feet below and 6 feet above the ground is perhaps the source of the proverb. Anyone carrying it would be bent double; hence figuratively, extreme or stooping old age'. 'He has become very old' would have been a perfectly adequate rendering.

Another such major and irresponsible editorial misinformation may be cited from Pradhan's edition. In Act V, Sc.i, Wood the planter kicks Gopinath the manager. After Wood leaves the scene, Gopinath comments: '...Oh! What kickings? Oh the fool is, as it were, the wife [wearing a gown]. of a student who is out of college'. The footnote runs as follows:

The wife... College: the enlightened Bengali wife of those days was a departure from the run of ordinary women, in so far as she would not easily submit to her husband, but would, on the contrary, demand submission from him -Ed (83).

This explanation has no historical support whatsoever. The idea of the enlightened wife dominating, or maltreating her husband had its origin in the contemporary Bangla popular songs and numerous farces expressing the anxiety of the orthodox guardians of society who were apprehensive of the effect of formal education of the women of Bengal. The statement could have been constructed more meaningfully in the context of the complex dynamics of the relationship between the oppressor and the oppressed. In this respect, within the scope of this paper, I can only draw attention to the 
note appended to this line by Long. The politics of interpretation is evident in the editorial avowal, 'This is said only in reference to his (Wood's) dress ' (Mitra 84, note 53; my emphasis). The carrying over (translation) of Wood to the domain of the wife would be feminizing the 'masculine AngloSaxon race' through the counter-gaze of the colonized other. The Raos have acknowledged the difficulty of decoding the lines by expunging them from their edition.

Unless translators translating from Indian regional languages into target languages (mostly English) work with special caution, they might disseminate incorrect information as in the cases mentioned above. ${ }^{10}$ Re-dressing a vernacular text for a larger, multicultural reading public the translator represents a text, a culture for a global market: the value of the translated text as a disseminator of cultural identity/history depends much on the ethics of the translator.

\section{Notes}

1. Quoted from The Blue Devil. (148). For complete details see the list of works cited. Unless otherwise stated, all citations with only the page no. in parenthesis are from this book. For the discussion of a major part of the contextual/historical matter, I have deliberately confined my references to this book as it draws on most of the important material available in English on the textual and contextual issues. Since my paper discusses their translation as well, interested readers may find it easier to locate contextual details in the same book. Those interested in looking up the original sources may consult the exhaustive bibliography provided in this book. 
2. Two, spellings are used: Nil Durpan as in Long's edition and Neel Darpan by the Raos - the latter retain the long 'e' sound of the Bangla word.

3. The missionaries considered the planters obstacles to their mission. Since the planters were also Christians the natives did not easily believe in the efficacy of Christianity. The animosity between the missionary and the planters was well known, and this was one of the main causes leading to Long's trial.

4. The oppression in the colonies hardly sustains this claim.

5. Besides Bankim Chandra Chattopadhyay the novelist's comment that Madhusudan Dutt translated the play, there is no other evidence or supportive document in favour of the claim.

6. Simpkin, Marshal \& Co, London 1862; Messers. A.N. Andini \& Co. Calcutta, 1903; Pradhan and Sailesh Ch. Sengupta, Eastern Trading Co., Calcutta 1953-54; and Sankar Sengupta, Indian Publications, Calcutta, 1972.

7. The authors do not mention the source of the lines quoted. They are from the poem 'Literature will be Scrutinized' from Martin Andersen Mexo. Brechi Poems, (ed) by John Willett and Ralph Manheim, 1981 repr. Radhakrishna Prakashan, New Delhi, I owe the information to Dr. Ramkrishna Bhattacharya, Anandamohan College, Kolkata. 
8. Bangiya Sabdakosh, p.68. All editions of the Bangla original explain the proverb in the correct sense.

9. I owe the explanation to Sri Madhusudhan Verantatirtha.

10. There are many such examples, which may be cited: there is a reference to 'Rajah' in Act I, Scene IV. (Radhakanta Deb and others who were the leaders opposing widow remarriage). This has been translated as 'king'. 'Rajah' in this context is a conferred title, which has only to be transliterated, and not translated.

\section{References}

Ashcroft, Bill (2001). Post-Colonial Transformation. NewYork: Routledge.

Bassnet, Susan and André Lefevere (ed) (1990). Translation, History and Culture. London: Pinter.

Mitra, S (2001). Prasanga Nil Durpan. Kolkata: Doorbar Kalam.

Pradhan, S \& Sengupta. S.C. (1958). Nil Durpan. Calcutta: Indian Publications.

Pradhan, S (1997). Nil Durpan, or The Indigo Planting Mirror, A Drama Translated from the Bengali by a Native. Calcutta: PashimBanga Natya Academi, Dept. of Information and Cultural Affairs, Govt. of West Bengal. 
Rao, A. \& Rao B.G. (1992). The Blue Devil: Indigo and Colonial Bengal. Trans.Dinabandhu Mitra Calcutta, Bombay, Madras: OUP.

Sengupta, S.C (1972). Nil Durpan or the Indigo Planting Mirror by Dinabandha Mitra, Translation from the Bengali by a Native. Edited with an Introduction. Calcutta: Indian Publications.

Snell-Hornby, Mary (1995 [1990]). "Linguistic Transcoding or Cultural Transfer? A Critique of Translation Theory in Germany", in Bassnett, S. and Lefevere, A. (eds) Translation, History \& Culture. Great Britain: Cassell.

Tymckzo, Maria (2000 [1999]). "Post-colonial Writing and Literary Translation" in S Bassnett and H Trivedi (eds) Post-colonial Translation: Theory and Practice. London and New York: Routledge. 